\title{
Prevalence and correlates of diabetes mellitus and dyslipidaemia in a long-stay inpatient schizophrenia population in Singapore
}

Saleha Shafie ${ }^{1}$, BSocSci, Siau Pheng Lee $\underline{L}^{1}$, BA, Samantha Bee Cheng $\underline{O n g}^{2}$, BHS(Nurs), EMBA, Peizhi Wang ${ }^{1}$, MPH, Esmond Seow ${ }^{1}$, BA, Hui Lin Ong $^{1}$, BA, Siow Ann $\underline{\text { Chong }}^{1}$, MBBS, MMed, Mythily Subramaniam ${ }^{1}$, MBBS, MHSM

INTRODUCTION Patients with schizophrenia have shorter life expectancy and one of the main causes of death is cardiovascular disease (CVD). Modifiable risk factors for CVD include diabetes mellitus (DM) and dyslipidaemia. This study aimed to establish: (a) the prevalence and correlates of DM and dyslipidaemia; (b) the proportion of those whose condition was well controlled; and (c) the incidence of undiagnosed DM and dyslipidaemia in a long-stay inpatient schizophrenia population.

METHODS Data was collected to assess the physical health status of 110 inpatients with schizophrenia who had been in hospital for over one year. Information on sociodemographic characteristics, diagnosis of physical and mental illnesses, and current medications was obtained from their medical records. The overall prevalence of DM and dyslipidaemia was based on diagnosis in the medical records, current medications and fasting blood test results.

RESULTS The patient group was predominantly male (85.5\%), with a mean age of $55.9 \pm 9.9$ (range 25-90) years. Overall prevalence of DM and dyslipidaemia was $19.1 \%$ and $62.7 \%$, respectively. Multivariate logistic regression analysis showed that Malay (odds ratio [OR] 14.97) and Indian (OR 25.71) patients were significantly more likely to have DM when compared to Chinese patients.

CONCLUSION In comparison to the general population, the prevalence of DM and dyslipidaemia was found to be higher in inpatients with schizophrenia. However, the two chronic illnesses were well controlled in inpatients and few were undiagnosed, perhaps due to the regular monitoring, supervised diet and regular physical activities arranged for inpatients in the long-stay inpatient wards.

Keywords: diabetes mellitus, dyslipidaemia, long-stay inpatients, schizophrenia

\section{INTRODUCTION}

Schizophrenia is a severe, debilitating mental disorder that affects about $1 \%$ of the general population worldwide. ${ }^{(1)}$ This illness is usually characterised by delusions, hallucinations, disorganised speech and behaviour, and other symptoms that cause social or occupational dysfunction. ${ }^{(2)}$ Although the prevalence is low, schizophrenia places an enormous burden on the individual and society, both in terms of human suffering and economic cost. In 2003, the Australian Low Prevalence (Psychotic) Disorders Study group reported that psychosis cost the Australian government at least AUD 1.45 billion per annum, while societal costs were at least AUD 2.25 billion per annum. ${ }^{(3)}$ Societal costs include loss of productivity in patients and their family, and costs to the healthcare system and the social and judicial sectors.

Medical advances in the past decades have led to improvement in healthcare and increase of average life expectancy of an individual, from 65 to 71 years. ${ }^{(4)}$ However, healthcare services for individuals with schizophrenia have not improved in parallel. When compared to the general population, patients with schizophrenia have a shorter life expectancy, with a difference of 10-25 years ${ }^{(5)}$ and a 2-3-times higher risk of death. ${ }^{(6-8)}$ Although there is a high suicide rate, a greater portion of deaths is accounted for by natural causes of death, including cardiovascular disease (CVD), as established in a meta-analysis by Brown. ${ }^{(9)} \mathrm{A}$ recent review by Bushe et al similarly found that the main causes of mortality in schizophrenia were suicide, cancer and CVD. ${ }^{(10)}$

Diabetes mellitus (DM), hypertension, obesity, hypercholesterolaemia and smoking are highly associated with CVD, and patients with schizophrenia have been found to have an increased risk for these risk factors. ${ }^{(11)}$ The high prevalence of these comorbidities can be attributed to antipsychotic medication, lifestyle (e.g. poor diet, lack of exercise and higher prevalence of smoking) and genetic factors. People with mental illness are often hindered from receiving good physical healthcare. Those with schizophrenia are less likely to report physical symptoms spontaneously compared to healthy control patients, and some symptoms that are consequences of schizophrenia (e.g. cognitive impairment, social isolation and suspicion) may contribute to them not seeking care or complying with treatment. ${ }^{(12)}$

One of the side effects of antipsychotics is weight gain ${ }^{(13-16)}$ and the subsequent predisposition to obesity. Patients with schizophrenia are often prescribed antidepressants and mood stabilisers, ${ }^{(17)}$ which are associated, although to a lesser degree, with an increased risk for several physical diseases that include DM and dyslipidaemia,

${ }^{1}$ Research Division, ${ }^{2}$ Nursing Administration, Institute of Mental Health, Singapore

Correspondence: Ms Saleha Shafie, Senior Research Officer, Research Division, Institute of Mental Health, 10 Buangkok View, Singapore 539747. saleha_shafie@imh.com.sg 
which are often linked to changes in body weight. ${ }^{(18,19)}$ In terms of their physical health, patients with schizophrenia have higher body mass index, ${ }^{(20-22)}$ and higher prevalence of DM, ${ }^{(23-26)}$ dyslipidaemia ${ }^{(27)}$ and $\mathrm{CVD}^{(28)}$ as compared to the general population. Furthermore, studies have also suggested that these patients have a lower probability of being screened and treated for such conditions, as reflected in a study by Nasrallah et al, ${ }^{(29)}$ where they found low treatment rates for dyslipidaemia and DM among patients with schizophrenia.

The aims of this study were to establish: (a) the prevalence and correlates of DM and dyslipidaemia, and the risk for DM and CVD in a long-stay inpatient population with schizophrenia; (b) the proportion of inpatients whose DM and dyslipidaemia were well controlled; and (c) the prevalence of undiagnosed DM and dyslipidaemia in this population.

\section{METHODS}

Data was collected as part of the study to assess the physical health status and functioning of inpatients with schizophrenia or schizoaffective disorder, who had stayed in long-stay wards for a minimum of one year at the Institute of Mental Health, Singapore. Patients staying in the long-stay ward mostly suffer from severe mental illness; their family members find it difficult to manage them at home and they need highly structured nursing care, ${ }^{(30)}$ thus resulting in prolonged hospitalisation.

Inclusion criteria included patients in the age group of 21-99 years, and those who were able to speak and understand English, Malay or Chinese. Inpatients with intellectual disability or dementia were excluded from the study. Research staff requested nursing staff in the long-stay wards to screen and refer patients who would be able to understand the principles and give consent on whether they were willing to participate in our study. From this list, the research staff ensured that patients met the eligibility criteria before approaching to recruit them for the study. During consent-taking, patients' understanding of informed consent was ascertained by being asked questions about the contents of the consent form. The response rate for the study was $73.2 \%$, and the main reason for not providing consent was patients' unwillingness to have a blood test done. Written consent was obtained from all inpatients. Ethics approval for the study was given by the National Healthcare Group Domain Specific Review Board.

Sociodemographic characteristics of the patients, such as age, gender, ethnicity, education, marital status, diagnosis of physical and mental illnesses, duration of illness, length of stay and details of current medications (including antipsychotics, antidepressants and mood stabilisers) were obtained from their medical records. The antipsychotic medications taken by patients were classified into six levels according to type and by chlorpromazine (CPZ) dosage: typical high; typical low; atypical high; atypical low; atypical and typical (combined) high; and atypical and typical (combined) low. All antipsychotic medications were converted to CPZ-equivalent doses. ${ }^{(31-35)}$ The CPZ-equivalent dose of the medication was then classified as low dose (range 1-299 mg) or high dose ( $\geq 300 \mathrm{mg}$ ) of antipsychotic medications. ${ }^{(36)}$
Height and weight were measured with patients wearing light clothing without shoes, using a measuring tape and a digital weighing scale, respectively. Body mass index was calculated as weight in kilograms divided by height in metres squared $\left(\mathrm{kg} / \mathrm{m}^{2}\right)$. Asian cut-offs for body mass index ${ }^{(37)}$ were used to identify those with moderate and high risk of DM and CVD.

Diagnosis of DM and dyslipidaemia was based on inpatients' medical records and their current medication use. The overall prevalence of DM and dyslipidaemia was established by determining fasting blood glucose and lipid levels after overnight fasting. Lipid profile and glucose were measured with Siemens Advia Chemistry system (Siemens ADVIA ${ }^{\circledR}$ Chemistry XPT System, Siemens Healthcare $\mathrm{GmbH}$, Erlangen, Germany) using enzymatic method. Glycated haemoglobin (HbA1c) level was measured with Bio Rad Variant 11 (Bio Rad D100, Bio-Rad Laboratories Inc, CA, USA) using high-performance liquid chromatography.

The overall prevalence of DM was based on the patients' medical records, prescription of medications to treat DM, including insulin injection, and fasting glucose level $\geq 7.0 \mathrm{mmol} / \mathrm{L}$. ${ }^{(38)}$ Similarly, the overall prevalence of dyslipidaemia was based on the medical records, current medications to treat dyslipidaemia (e.g. fenofibrate, gemfibrozil, simvastatin and lovastatin) and a total cholesterol level $\geq 6.2 \mathrm{mmol} / \mathrm{L}$. ${ }^{(38)}$ High-density lipoprotein cholesterol (HDL-C) levels $<1.0 \mathrm{mmol} / \mathrm{L}$ or $<40 \mathrm{mg} / \mathrm{dL}$ is considered to be a risk factor for coronary heart disease, ${ }^{(39)}$ and Rosenson $^{(40)}$ has suggested that raising HDL-C levels should be a secondary target of dyslipidaemia therapy. Accordingly, low $\mathrm{HDL}-\mathrm{C}$ level, defined as $<1.0 \mathrm{mmol} / \mathrm{L}$ or $<40 \mathrm{mg} / \mathrm{dL}_{,}{ }^{(41)}$ was also assessed.

Statistical analysis was conducted using IBM SPSS Statistics 21.0 (IBM Corp, Armonk, NY, USA). The inpatients' sociodemographic characteristics were obtained by descriptive statistics. Multivariate logistic regression analyses were done to examine the effects of sociodemographic characteristics, risk for DM and CVD, antipsychotic medication type by total daily CPZ-equivalent dose, antidepressants and mood stabilisers on medical conditions (i.e. DM and dyslipidaemia). Sociodemographic characteristics, including age group, gender, ethnicity, marital status and education level were entered in the first block to predict DM, dyslipidaemia, and risk for DM and CVD. Subsequently, antipsychotic medication type by CPZ equivalents, antidepressants and mood stabilisers were entered in the second block, and the risk for DM and CVD was entered in the third block to predict DM and dyslipidaemia while controlling for independent variables entered in the first, second and third blocks.

\section{RESULTS}

Among 110 long-stay inpatients with schizophrenia or schizoaffective disorder, $85.5 \%$ were men. Mean age of patients was $55.9 \pm 9.9$ (range $25-90$ ) years. The majority of patients were ethnically Chinese (80.0\%), single (76.4\%), and had moderate or high risk for DM and CVD (46.4\%). More than half of our patients had primary education or less, with $30.0 \%$ and $38.2 \%$ of patients 
Table I. Sociodemographic distribution of long-stay inpatients with schizophrenia or schizoaffective disorder $(n=110)$.

\begin{tabular}{|c|c|}
\hline Variable & No. (\%) \\
\hline \multicolumn{2}{|l|}{ Age group (yr) } \\
\hline $21-59$ & $67(60.9)$ \\
\hline $60-99$ & $43(39.1)$ \\
\hline \multicolumn{2}{|l|}{ Gender } \\
\hline Female & $16(14.5)$ \\
\hline Male & $94(85.5)$ \\
\hline \multicolumn{2}{|l|}{ Ethnicity } \\
\hline Chinese & $88(80.0)$ \\
\hline Malay & $16(14.5)$ \\
\hline Indian & $6(5.5)$ \\
\hline \multicolumn{2}{|l|}{ Marital status } \\
\hline Single & $84(76.4)$ \\
\hline Married & $5(4.5)$ \\
\hline Divorced/separated & $18(16.4)$ \\
\hline Widowed & $3(2.7)$ \\
\hline \multicolumn{2}{|l|}{ Education } \\
\hline Nil & $33(30.0)$ \\
\hline Primary & $42(38.2)$ \\
\hline Secondary & $13(11.8)$ \\
\hline Vocational & $10(9.1)$ \\
\hline Junior college/polytechnic/university & $12(10.9)$ \\
\hline \multicolumn{2}{|l|}{ Body mass index $\left(\mathbf{k g} / \mathbf{m}^{2}\right)$} \\
\hline $\begin{array}{l}<18.5 \text { (at risk of nutritional deficiency diseases and } \\
\text { osteoporosis) }\end{array}$ & $12(10.9)$ \\
\hline 18.5-22.9 (low risk) & $47(42.7)$ \\
\hline 23.0-27.4 (moderate risk) & $39(35.5)$ \\
\hline$\geq 27.5$ (high risk) & $12(10.9)$ \\
\hline \multicolumn{2}{|c|}{ Antipsychotic medication type by chlorpromazine dosage } \\
\hline Typical high & $30(27.3)$ \\
\hline Typical low & $18(16.4)$ \\
\hline Atypical high & $11(10.0)$ \\
\hline Atypical low & $9(8.2)$ \\
\hline Atypical and typical (combined) high & $38(34.5)$ \\
\hline Atypical and typical (combined) low & $1(0.9)$ \\
\hline No medication & $3(2.7)$ \\
\hline \multicolumn{2}{|l|}{ Antidepressant } \\
\hline No & $88(80.0)$ \\
\hline Yes & $22(20.0)$ \\
\hline \multicolumn{2}{|l|}{ Mood stabiliser } \\
\hline No & $69(62.7)$ \\
\hline Yes & $41(37.3)$ \\
\hline
\end{tabular}

indicating no education and primary education, respectively. The sociodemographic characteristics of the sample are provided in Table I. Mean duration of illness was $28.0 \pm 11.5$ (range 3-63) years and mean length of stay in the long-stay ward was $99.9 \pm$ 81.2 (range 12-348) months.

In multivariate logistic regression analysis, it was found that Malay (odds ratio [OR] 14.97) and Indian (OR 25.71) patients, when compared to Chinese patients, were significantly more likely to have DM. Patients taking antidepressants (OR 4.56), when compared to patients not taking antidepressants, were found to be significantly associated with dyslipidaemia. The sociodemographic and medical correlates of DM, dyslipidaemia, and moderate and high risk for DM and CVD are given in Table II.

The prevalence of DM among inpatients, based on patients' medical records and current medications, was $17.3 \%(\mathrm{n}=19)$, of which $5.3 \%(n=1)$ of patients had poor blood sugar control (defined as $\mathrm{HbA} 1 \mathrm{c}>8.0 \%$ ) (Table III). Of the $82.7 \%(\mathrm{n}=91)$ of inpatients who were undiagnosed based on medical records and current medications, $2.2 \%(\mathrm{n}=2)$ were found to have DM (defined as fasting glucose levels $\geq 7.0 \mathrm{mmol} / \mathrm{L}$ ). Thus, the overall prevalence of DM among inpatients, including those diagnosed through fasting blood test, was $19.1 \%(n=21)$ in our study.

The prevalence of dyslipidaemia in inpatients, based on medical records and current medications, was $62.7 \%(n=69)$, of which $87.0 \%(n=60)$ of patients had normal total cholesterol (defined as total cholesterol $<5.2 \mathrm{mmol} / \mathrm{L}$ ). None of those undiagnosed patients $(n=41)$, as per the medical records and current medications, were found to have dyslipidaemia through the fasting blood test (defined as total cholesterol $\geq 6.2 \mathrm{mmol} / \mathrm{L}$ ). Thus, the overall prevalence of dyslipidaemia, including fasting blood test, was $62.7 \%(n=69)$ in our patients. The prevalence of low HDL-C in inpatients was $27.7 \%$ (defined as HDL-C $<1.0 \mathrm{mmol} / \mathrm{L}$ or $40 \mathrm{mg} / \mathrm{dL}$ ).

\section{DISCUSSION}

The prevalence of DM in our inpatients with schizophrenia $(19.1 \%)$ was found to be higher than in the Singapore general population $(11.3 \%) .{ }^{(41)} \mathrm{DM}$ was defined as patients with two-hour plasma glucose concentration $\geq 11.1 \mathrm{mmol} / \mathrm{L}$ or $\geq 200 \mathrm{mg} / \mathrm{dL}$ or who were known diabetic patients on medication in the 2010 National Health Survey in Singapore. ${ }^{(41)}$ This finding was similar to previous studies on long-stay psychiatric inpatients in Singapore ${ }^{(26)}$ and the Netherlands, ${ }^{(25)}$ where the prevalence of DM was $16 \%$ and $15 \%$, respectively. The general population had poorer blood control compared to inpatients. It was found that $32.0 \%$ of the general population ${ }^{(41)}$ had poor blood sugar control compared to $5.3 \%$ of our inpatients. Table IV provides the descriptive prevalence comparisons for DM and dyslipidaemia between the two studies referred here.

Similarly, the prevalence of dyslipidaemia among inpatients with schizophrenia $(62.7 \%)$ was higher than that of the general population (26.9\%). ${ }^{(41)}$ Dyslipidaemia was defined as patients who had total cholesterol levels $\geq 6.2 \mathrm{mmol} / \mathrm{L}$ or $\geq 240 \mathrm{mg} / \mathrm{dL}$, or those known to have high cholesterol and were being prescribed medicine in the 2010 National Health Survey. ${ }^{(41)}$ This was in line with another study on inpatients treated with antipsychotics, which found that $66.7 \%$ of them had dyslipidaemia. ${ }^{(27)} \mathrm{A}$ higher proportion of inpatients in our study had good control of their cholesterol level when compared to the general population $87.0 \%$ of inpatients had normal total cholesterol levels compared to $42.3 \%$ in the general population.

Although the prevalence of DM and dyslipidaemia were found to be higher in inpatients, these two chronic illnesses were well 
Table II. Sociodemographic and medical correlates of DM, dyslipidaemia, and moderate and high risk for DM and CVD among long-stay inpatients with schizophrenia or schizoaffective disorder.

\begin{tabular}{|c|c|c|c|c|c|c|}
\hline \multirow[t]{2}{*}{ Variable } & \multicolumn{2}{|l|}{ DM } & \multicolumn{2}{|c|}{ Dyslipidaemia } & \multicolumn{2}{|c|}{$\begin{array}{c}\text { Moderate and high risk for } \\
\text { DM and CVD }\end{array}$} \\
\hline & $\mathrm{OR}^{*}(95 \% \mathrm{CI})$ & p-value & $\mathrm{OR}^{*}(95 \% \mathrm{CI})$ & p-value & OR* $(95 \% \mathrm{CI})$ & p-value \\
\hline \multicolumn{7}{|l|}{ Age group (yr) } \\
\hline $21-59$ & Ref & & Ref & & Ref & \\
\hline $60-99$ & $1.95(0.43-8.91)$ & 0.390 & $1.16(0.41-3.31)$ & 0.786 & $1.73(0.61-4.90)$ & 0.301 \\
\hline \multicolumn{7}{|l|}{ Gender } \\
\hline Female & Ref & & Ref & & Ref & \\
\hline Male & $1.09(0.14-8.36)$ & 0.936 & $0.49(0.11-2.10)$ & 0.333 & $0.76(0.19-3.13)$ & 0.706 \\
\hline \multicolumn{7}{|l|}{ Ethnicity } \\
\hline Chinese & Ref & & Ref & & Ref & \\
\hline Malay & $14.97(1.46-153.90)$ & $0.023^{+}$ & $0.43(0.10-1.94)$ & 0.272 & $1.70(0.38-7.48)$ & 0.486 \\
\hline Indian & $25.71(2.22-297.44)$ & $0.009^{\dagger}$ & $0.77(0.09-6.37)$ & 0.807 & $0.88(0.12-6.58)$ & 0.897 \\
\hline \multicolumn{7}{|l|}{ Marital status } \\
\hline Single & Ref & & Ref & & Ref & \\
\hline Married & $1.50(0.09-25.26)$ & 0.780 & $0.19(0.02-1.59)$ & 0.125 & $4.42(0.38-51.47)$ & 0.236 \\
\hline Divorced/separated & $0.44(0.07-2.72)$ & 0.378 & $0.97(0.24-3.97)$ & 0.961 & $1.09(0.29-4.08)$ & 0.896 \\
\hline Widowed & $0.45(0.01-26.87)$ & 0.700 & - & 0.999 & $0.86(0.06-12.76)$ & 0.915 \\
\hline \multicolumn{7}{|l|}{ Education } \\
\hline Nil & Ref & & Ref & & Ref & \\
\hline Primary & $1.66(0.41-6.66)$ & 0.474 & $0.71(0.24-2.11)$ & 0.533 & $0.52(0.18-1.48)$ & 0.222 \\
\hline Secondary & - & 0.998 & $0.71(0.16-3.10)$ & 0.647 & $2.36(0.48-11.58)$ & 0.291 \\
\hline Vocational & $0.17(0.09-3.23)$ & 0.236 & $0.82(0.14-5.05)$ & 0.835 & $0.53(0.09-3.12)$ & 0.483 \\
\hline $\begin{array}{l}\text { Junior college/ } \\
\text { polytechnic/university }\end{array}$ & $3.07(0.34-28.09)$ & 0.320 & $0.71(0.14-3.51)$ & 0.675 & $0.29(0.05-1.57)$ & 0.150 \\
\hline \multicolumn{7}{|l|}{$\begin{array}{l}\text { Antipsychotic medication } \\
\text { type by CPZ dosage }\end{array}$} \\
\hline Typical high & Ref & & Ref & & Ref & \\
\hline Typical low & $1.24(0.23-6.83)$ & 0.803 & $1.83(0.43-7.89)$ & 0.415 & $0.34(0.08-1.51)$ & 0.156 \\
\hline Atypical high & - & 0.999 & $1.91(0.40-9.00)$ & 0.416 & $1.13(0.24-5.38)$ & 0.875 \\
\hline Atypical low & $0.71(0.07-6.76)$ & 0.765 & $1.65(0.28-9.76)$ & 0.583 & $0.67(0.13-3.51)$ & 0.633 \\
\hline $\begin{array}{l}\text { Atypical and typical } \\
\text { (combined) high }\end{array}$ & $0.58(0.12-2.74)$ & 0.490 & $1.44(0.47-4.43)$ & 0.525 & $0.76(0.25-2.28)$ & 0.620 \\
\hline $\begin{array}{l}\text { Atypical and typical } \\
\text { (combined) low }\end{array}$ & 0.42 & 1.000 & - & 1.000 & - & 1.000 \\
\hline \multicolumn{7}{|l|}{ Antidepressant } \\
\hline No & Ref & & Ref & & Ref & \\
\hline Yes & $1.78(0.39-8.20)$ & 0.457 & $4.56(1.22-16.97)$ & $0.024^{\dagger}$ & $0.43(0.13-1.46)$ & 0.175 \\
\hline \multicolumn{7}{|l|}{ Mood stabiliser } \\
\hline No & Ref & & Ref & & Ref & \\
\hline Yes & $0.74(0.19-2.94)$ & 0.673 & $0.97(0.37-2.52)$ & 0.952 & $2.53(0.96-6.69)$ & 0.061 \\
\hline \multicolumn{7}{|l|}{$\begin{array}{l}\text { Moderate and high risk } \\
\text { for DM and CVD }\end{array}$} \\
\hline No & Ref & & Ref & & - & - \\
\hline Yes & $1.37(0.40-4.65)$ & 0.620 & $2.13(0.85-5.33)$ & 0.108 & - & - \\
\hline
\end{tabular}

*OR was calculated using multivariate logistic regression analysis. $\mathrm{tp}<0.05$ was considered to be statistically significant. Cl: confidence interval; CPZ: chlorpromazine; CVD: cardiovascular disease; DM: diabetes mellitus; OR: odds ratio

controlled among inpatients with schizophrenia when compared to the general population. Also, few inpatients were undiagnosed for DM while none were undiagnosed for dyslipidaemia in our study. This could be due to the high standard of care coupled with the routines and conditions prevalent in our wards, as smoking is strictly prohibited, patients are regularly monitored for physical illness, patient diet is supervised and patients regularly exercise. Patients with DM also have meals tailored to their 
needs. For a majority of inpatients with dyslipidaemia, the first line of treatment is through diet control; only when diet control is deemed ineffective are patients prescribed medication. Patients on medications, however, continue to have their diets controlled.

Inpatients of Indian and Malay ethnicities were more likely to have DM when compared to Chinese patients. However, other variables, such as moderate and high risk for DM and CVD, antipsychotic medication type by total daily CPZ-equivalent dose, antidepressants and mood stabilisers, were not significantly associated with DM. It appears that ethnicity was the only factor that affected DM, but not dyslipidaemia, in our inpatient population. It should be noted, though, that due to our small sample size, the OR might have been inflated. Gordóvil-Merino

Table III. Prevalence of diabetes mellitus and dyslipidaemia among long-stay inpatients with schizophrenia or schizoaffective disorder $(n=110)$.

\begin{tabular}{|ll|}
\hline Variable & No. (\%) \\
\hline Diabetes mellitus & \\
\hline Known inpatients with DM & $19 / 110(17.3)$ \\
\hline Poor blood sugar control & $1 / 19(5.3)$ \\
\hline Undiagnosed inpatients with DM & $2 / 91(2.2)$ \\
\hline Overall prevalence & $21 / 110(19.1)$ \\
\hline Dyslipidaemia & \\
\hline Known inpatients with dyslipidaemia & $69 / 110(62.7)$ \\
\hline Total cholesterol in control & $60 / 69(87.0)$ \\
\hline Undiagnosed inpatients with dyslipidaemia & $0 / 41(0)$ \\
\hline Overall prevalence & $69 / 110(62.7)$ \\
\hline Low HDL-C & $30 / 108^{*}(27.7)$ \\
\hline
\end{tabular}

*Data from two respondents was missing. HDL-C: high-density lipoprotein cholesterol et $\mathrm{al}^{(42)}$ have suggested that Bayesian estimations in logistic regression would be able to provide more stable distributions. However, they found that this was still unable to solve problems generated by asymmetric distributions based on small samples. As this simulation only involved two independent variables (IVs) (a binary IV and a continuous IV), it may need further investigation. Further studies are therefore necessary to confirm the association found in our population between DM and ethnicity. Yet, other studies in the Singapore general population, such as the National Health Survey conducted every few years in Singapore, observed a similar trend in differences between the ethnic groups. ${ }^{(41)}$ For the 1992, ${ }^{(43)} 1998,{ }^{(44)} 2004^{(45)}$ and 2010 editions, there was a consistent trend, where Indian persons had the highest prevalence of DM, followed by Malay and Chinese persons in that order. For example, in the recent 2010 survey, ${ }^{(41)}$ the prevalence of DM was $17.2 \%$ for Indian, $16.6 \%$ for Malay and $9.7 \%$ for Chinese people. In their review paper, Misra and Vikram ${ }^{(46)}$ found that Asian Indians have a high prevalence of insulin resistance syndrome, which may be the basis of their greater than normal tendency to develop DM and early atherosclerosis. Similarly, Indians were more prone to develop central obesity with insulin resistance and glucose intolerance compared to the Malays and Chinese in a study from Singapore. ${ }^{(47)}$ In another Singapore study that examined ethnic differences among patients with DM, the authors found that Malay patients had the highest body mass index while Indian patients had the highest $\mathrm{HbA} 1 \mathrm{c}$ levels and were more likely to have a positive family history of DM. ${ }^{(48)}$

The prevalence of low HDL-C was $27.7 \%$ and $8.1 \%$ in our inpatients and the general Singapore population, ${ }^{(41)}$ respectively, suggesting that lower HDL-C levels were more common among long-stay inpatients with schizophrenia. This may

Table IV. Descriptive comparison of the prevalence of DM and dyslipidaemia

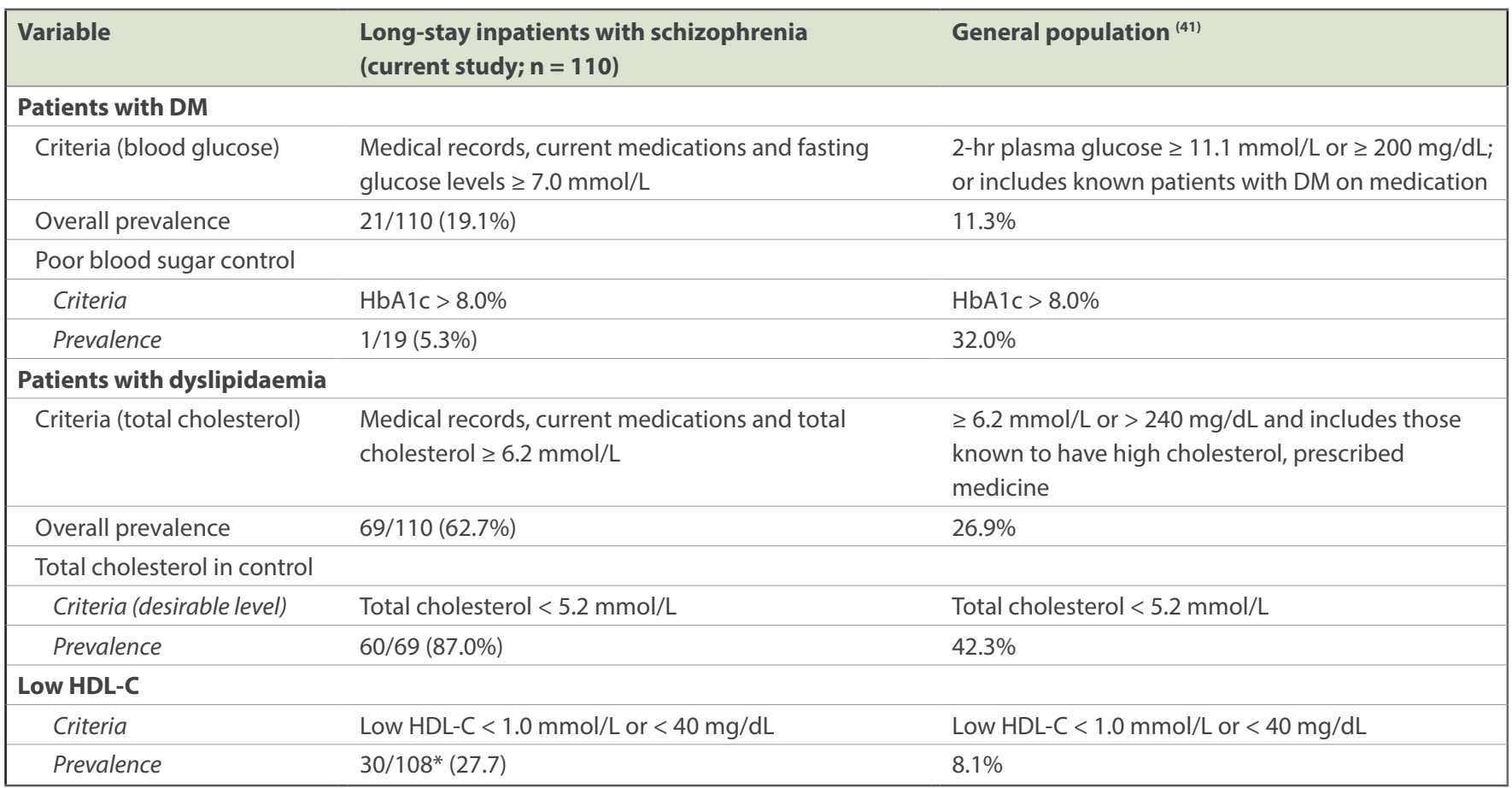

*Data from two respondents was missing. DM: diabetes mellitus; HbA1c: glycated haemoglobin; HDL-C: high-density lipoprotein cholesterol 
indicate a hitherto unappreciated higher risk of coronary heart disease among these inpatients when compared to the general population. Some interventions suggested by Rosenson ${ }^{(40)}$ to raise HDL-C levels were through therapeutic lifestyle changes (including smoking cessation, weight loss, exercise and diet) and pharmacological interventions (including statins, fibrates and niacin). Clinical endpoint studies that involved the use of statins, fibrates and nicotinic acid have indicated the benefit of raising low HDL-C plasma levels in patients with or at risk of premature coronary heart disease. ${ }^{(49)}$ These were used either as monotherapy or in combination, and nicotinic acid was found to be the most potent agent for raising HDL-C. Antidepressants were found to be significantly associated with dyslipidaemia. Unfortunately, there is scant evidence in previous literature about the association between antidepressants use and dyslipidaemia, among those with schizophrenia. Certain antidepressants such as fluoxetine, fluvoxamine and sertraline were found to be associated with abdominal obesity and hypercholesterolemia in a general population study. ${ }^{(50)}$ Among patients with generalised anxiety disorder, Beyazyüz et al $^{(51)}$ studied the effects of selective serotonin reuptake inhibitors on metabolic parameters after 16 weeks of treatment and found that the level of total cholesterol was significantly increased for patients taking sertraline, while patients taking paroxetine had a significant increase in a number of parameters including total cholesterol, low-density lipoprotein and triglycerides. Therefore, patients with psychosis, when prescribed a combination of antipsychotics with antidepressants, need to be regularly monitored for weight gain, DM and dyslipidaemia. Cormac et al ${ }^{(52)}$ provided suggestions on health promotion activities, which included smoking cessation, physical activity, diet and weight management, to be implemented to improve physical health of long-stay patients. There is strong evidence that shows the effectiveness of lifestyle interventions through diet and exercise for managing risk factors of CVDs in patients with severe mental illness. ${ }^{(53)}$ As earlier mentioned, smoking is strictly prohibited in our wards. Inpatients' weight and physical illnesses (e.g. DM and dyslipidaemia) should continue to be monitored, and their diet and exercises planned to manage such comorbidities. Thus, management of these physical illnesses in inpatients will help in maintaining good physical health for patients with schizophrenia and subsequently contribute to lowering of excess mortality through a reduction in CVD. In general, our study underscores the benefits of long-term care in managing patients' physical illnesses by regulating diet and physical activities.

Some of the limitations of this study were its small sample size and predominantly male sample. Inpatients who were cognitively impaired, had behavioural issues, were unable to speak and understand English, Chinese or Malay, and those unable to give consent were not recruited into the study. This reduced the number of patients that was approached for inclusion. Thus, our results should be interpreted with caution, as it may not be generalisable to patient populations who are unable to provide consent or unable to complete the self-administered questionnaires.
Notwithstanding the limitations stated above, this study is one of the few single-site studies done in a long-stay psychiatric hospital in Singapore. Given that long-stay inpatients with schizophrenia are an extremely vulnerable group, it was ensured that only patients who were cognitively able to provide consent were recruited. Multiple languages were used to ensure more patients were included in the study. All measurements were carried out using standardised procedures by trained staff, and laboratory investigations were performed on all patients using an accredited centralised laboratory. Further studies, with a bigger sample size, should be done to understand more about the associations between physical and mental illness and the interventions that can be implemented to improve patients' health.

\section{ACKNOWLEDGEMENT}

This research was supported by the Singapore Ministry of Health's National Medical Research Council under the Centre Grant Programme (grant no. NMRC/CG/004/2013).

\section{REFERENCES}

1. American Psychiatric Association. Diagnostic and Statistical Manual of Mental Disorders (DSM). Washington, DC: American Psychiatric Association, 1994.

2. American Psychiatric Association. Diagnostic and Statistical Manual of Mental Disorders (DSM-5®). Washington, DC: American Psychiatric Association, 2013.

3. Carr VJ, Neil AL, Halpin SA, Holmes S, Lewin TJ. Costs of schizophrenia and other psychoses in urban Australia: findings from the Low Prevalence (Psychotic) Disorders Study. Aust N Z J Psychiatry 2003; 37:31-40.

4. World Health Organization. Global Health Observatory $(\mathrm{GHO})$ data. Life expectancy. Available at: http://www.who.int/gho/mortality_burden_disease/ life_tables/situation_trends_text/en/. Accessed August 14, 2015

5. Laursen TM, Munk-Olsen T, Vestergaard M. Life expectancy and cardiovascular mortality in persons with schizophrenia. Curr Opin Psychiatry 2012; 25: 83-8.

6. Auquier P, Lançon C, Rouillon F, Lader M, Holmes C. Mortality in schizophrenia. Pharmacoepidemiol Drug Saf 2006; 15:873-9

7. Brown S, Kim M, Mitchell C, Inskip H. Twenty-five year mortality of a community cohort with schizophrenia. Br J Psychiatry 2010; 196:116-21.

8. Saha S, Chant D, McGrath J. A systematic review of mortality in schizophrenia: is the differential mortality gap worsening over time? Arch Gen Psychiatry 2007; 64:1123-31

9. Brown S. Excess mortality of schizophrenia. A meta-analysis. Br J Psychiatry 1997; 171:502-8.

10. Bushe CJ, Taylor M, Haukka J. Mortality in schizophrenia: a measurable clinical endpoint. J Psychopharmacol 2010; 24(4 Suppl):17-25.

11. De Hert M, Correll CU, Bobes J, et al. Physical illness in patients with severe mental disorders. I. Prevalence, impact of medications and disparities in health care. World Psychiatry 2011; 10:52-77.

12. Phelan M., Stradins L. Morrison S. Physical health of people with severe mental illness. BMJ 2001; 322:443-4.

13. Holt RI, Peveler RC. Obesity, serious mental illness and antipsychotic drugs. Diabetes Obes Metab 2009; 11:665-79.

14. Newcomer JW. Antipsychotic medications: metabolic and cardiovascular risk. J Clin Psychiatry 2007; 68 Suppl 4:8-13.

15. Verma S, Liew A, Subramaniam M, Poon LY. Effect of treatment on weight gain and metabolic abnormalities in patients with first-episode psychosis. Aust N Z J Psychiatry 2009; 43:812-7.

16. Subramaniam M, Lam M, Guo ME, et al. Body mass index, obesity, and psychopathology in patients with schizophrenia. J Clin Psychopharmacol 2014; 34:40-6.

17. Mojtabai R, Olfson M. National trends in psychotropic medication polypharmacy in office-based psychiatry. Arch Gen Psychiatry 2010; 67:26-36.

18. Correll CU, Detraux J, De Lepeleire J, De Hert M. Effects of antipsychotics, antidepressants and mood stabilizers on risk for physical diseases in people with schizophrenia, depression and bipolar disorder. World Psychiatry 2015; 14:119-36.

19. McIntyre RS, Soczynska JK, Konarski JZ, Kennedy SH. The effect of antidepressants on lipid homeostasis: a cardiac safety concern? Expert opinion on drug safety. 2006; 5:523-37.

20. Coodin S. Body mass index in persons with schizophrenia. Can J Psychiatry $2001 ; 46: 549-55$ 
21. Limosin F, Gasquet I, Leguay D, Azorin JM, Rouillon F. Body mass index and prevalence of obesity in a French cohort of patients with schizophrenia. Acta Psychiatr Scand 2008; 118:19-25.

22. Strassnig M, Brar JS, Ganguli R. Body mass index and quality of life in community-dwelling patients with schizophrenia. Schizophr Res 2003; 62:73-6.

23. Bushe C, Holt R. Prevalence of diabetes and impaired glucose tolerance in patients with schizophrenia. Br J Psychiatry Suppl 2004; 47:S67-71.

24. Dixon L, Weiden P, Delahanty J, et al. Prevalence and correlates of diabetes in national schizophrenia samples. Schizophr Bull 2000; 26:903-12.

25. Mookhoek EJ, de Vries WA, Hovens JE, Brouwers JR, Loonen AJ. Risk factors for overweight and diabetes mellitus in residential psychiatric patients. Obes Facts $2011 ; 4: 341-5$

26. Subramaniam M, Chong SA, Pek E. Diabetes mellitus and impaired glucose tolerance in patients with schizophrenia. Can J Psychiatry 2003; 48:345-7.

27. Paton C, Esop R, Young C, Taylor D. Obesity, dyslipidaemias and smoking in an inpatient population treated with antipsychotic drugs. Acta Psychiatr Scand 2004; 110:299-305.

28. Bresee LC, Majumdar SR, Patten SB, Johnson JA. Prevalence of cardiovascular risk factors and disease in people with schizophrenia: a population-based study. Schizophr Res 2010; 117:75-82.

29. Nasrallah HA, Meyer JM, Goff DC, et al. Low rates of treatment for hypertension, dyslipidemia and diabetes in schizophrenia: data from the CATIE schizophrenia trial sample at baseline. Schizophr Res 2006; 86:15-22.

30. Chong SA, Subramaniam A. Staying relevant with the times--the changing face of an asylum. Ann Acad Med Singapore 2014; 43:481-3.

31. Atkins M, Burgess A, Bottomley C, Riccio M. Chlorpromazine equivalents: a consensus of opinion for both clinical and research applications. Psychiatr Bull 1997; 21:224-6.

32. Barnes TR, Paton C. Improving prescribing practice in psychiatry: the experience of the Prescribing Observatory for Mental Health (POMH-UK). Int Rev Psychiatry 2011; 23:328-35.

33. Chue $\mathrm{P}$, Eerdekens M, Augustyns I, et al. Comparative efficacy and safety of long-acting risperidone and risperidone oral tablets. Eur Neuropsychopharmacol 2005; 15:111-7.

34. Davis JM. Dose equivalence of the antipsychotic drugs. J Psychiatr Res 1974; 11:65-9.

35. Leucht S, Samara M, Heres S, et al. Dose equivalents for second-generation antipsychotics: the minimum effective dose method. Schizophr Bull 2014; 40:314-26.

36. Ikeno T, Kugiyama K, Ito $\mathrm{H}$. Antipsychotic medication and risk of QTC prolongation: focus on multiple medication and role of cytochrome P450 isoforms. Open J Psychiatry 2014; 4:381-9.

37. WHO Expert Consultation. Appropriate body-mass index for Asian populations and its implications for policy and intervention strategies. Lancet 2004; 363:157-63.

38. World Health Organization. Definition and diagnosis of diabetes mellitus and intermediate hyperglycaemia: report of a WHO/IDF consultation. Available at: http://www.who.int/diabetes/publications/Definition\%20and\%20diagnosis\%20 of\%20diabetes_new.pdf. Accessed May 29, 2015.
39. Expert Panel on Detection, Evaluation, and Treatment of High Blood Cholesterol in Adults. Executive summary of the third report of the National Cholesterol Education Program (NCEP) expert panel on detection, evaluation, and treatment of high blood cholesterol in adults (Adult Treatment Panel III). JAMA 2001; 285:2486-97.

40. Rosenson RS. Low HDL-C: a secondary target of dyslipidemia therapy. Am J Med 2005; 118:1067-77.

41. Ministry of Health, Singapore. National Health Survey 2010. Available at: https://www.moh.gov.sg/content/dam/moh_web/Publications/Reports/2011/ NHS2010\%20-\%20low\%20res.pdf. Accessed July 7, 2015.

42. Gordóvil-Merino A, Guàrdia-Olmos J, Peró-Cebollero M. Estimation of logistic regression models in small samples. A simulation study using a weakly informative default prior distribution. Psicologica 2012; 33:345-61.

43. Ministry of Health, Singapore. National Health Survey 1992: Highlights of main survey findings. Singapore: Research and Evaluation Department, Ministry of Health, 1993.

44. Ministry of Health, Singapore. National Health Survey 1998. Available at: https:// www.moh.gov.sg/content/dam/moh_web/Publications/Reports/1999/nhs.pdf. Accessed January 24, 2018.

45. Ministry of Health, Singapore. National Health Survey 2004. Available at: https://www.moh.gov.sg/content/dam/moh_web/Publications/Reports/2005/1/ NHS_2004(Part2).pdf. Accessed January 24, 2018.

46. Misra A, Vikram NK. Insulin resistance syndrome (metabolic syndrome) and obesity in Asian Indians: evidence and implications. Nutrition 2004; 20:482-91.

47. Hughes K, Aw TC, Kuperan P, Choo M. Central obesity, insulin resistance, syndrome $\mathrm{X}$, lipoprotein (a), and cardiovascular risk in Indians, Malays, and Chinese in Singapore. J Epidemiol Community Health 1997; 51:394-9.

48. Hong CY, Chia KS, Hughes K, Ling SL. Ethnic differences among Chinese, Malay and Indian patients with type 2 diabetes mellitus in Singapore. Singapore Med J 2004; 45:154-60.

49. Chapman MJ, Assmann G, Fruchart JC, Shepherd J, Sirtori C; European Consensus Panel of HDL-C. Raising high-density lipoprotein cholesterol with reduction of cardiovascular risk: the role of nicotinic acid--a position paper developed by the European Consensus Panel on HDL-C. Curr Med Res Opin 2004; 20:1253-68.

50. Raeder MB, Bjelland I, Emil Volsett S, Steen VM. Obesity, dyslipidemia, and diabetes with selective serotonin reuptake inhibitors: the Hordaland Health Study. J Clin Psychiatry 2006; 67:1974-82.

51. Beyazyüz M, Albayrak Y, Eğilmez OB, Albayrak N, Beyazyüz E. Relationship between SSRIs and metabolic syndrome abnormalities in patients with generalized anxiety disorder: a prospective study. Psychiatry Investig 2013; 10:148-54.

52. Cormac I, Martin D, Ferriter M. Improving the physical health of long-stay psychiatric in-patients. Adv Psychiatr Treat 2004; 10:107-15.

53. Chacón F, Mora F, Gervás-Ríos A, Gilaberte I. Efficacy of lifestyle interventions in physical health management of patients with severe mental illness. Ann Gen Psychiatry 2011; 10:22. 